\title{
Implantation of toric intraocular lenses in patients with cataract and keratoconus: a case series
}

This article was published in the following Dove Press journal: International Medical Case Reports Journal

\author{
Karin Allard' \\ Madeleine Zetterberg ${ }^{1,2}$ \\ 'Department of Ophthalmology, \\ Sahlgrenska University Hospital, \\ Mölndal, Sweden; ${ }^{2}$ Department of \\ Clinical Neuroscience/Ophtalmology, \\ Institute of Neuroscience and \\ Physiology, The Sahlgrenska \\ Academy, University of Gothenburg, \\ Gothenburg, Sweden
}

Purpose: To describe the results of phacoemulsification and implantation of toric intraocular lenses (IOLs) in patients with cataract and keratoconus.

Patients and methods: Prospective study of 4 patients ( 4 eyes) with cataract and keratoconus who underwent phacoemulsification with implantation of a toric IOL. Two different toric IOLs were used: AcrySof IQ SN6AT9 and AT Torbi 709M(P). Corneal tomography was performed preoperatively using Scheimpflug technique with Pentacam. Astigmatism was regular or slightly irregular in all patients. Postoperatively, best-corrected visual acuity (BCVA), astigmatism, spherical equivalent, and complications were recorded for all patients. Follow-up time was between 4 weeks and 7 months.

Results: BCVA increased and astigmatism decreased in all patients. BCVA increased from $20 / 50$ to $20 / 40$ in patient 1 , from $20 / 63$ to $20 / 20$ in patient 2 , from $20 / 40$ to $20 / 32$ in patient 3 , and from hand motion to $20 / 40$ in patient 4 . Astigmatism decreased from -6.12 to $-3.75 \mathrm{D}$ in patient 1 , from -4.62 to $-1.75 \mathrm{D}$ in patient 2 , from -9.0 to $-3.0 \mathrm{D}$ in patient 3 , and from -8.0 to $-2.75 \mathrm{D}$ in patient 4 . One patient developed pseudophakic cystoid macular edema, but at last follow-up after 6 months the edema had resolved. Another patient developed posterior capsular opacification after 2 months. No misalignment of the axis of the IOL was observed.

Conclusion: Correction of both astigmatism and cataract with phacoemulsification and implantation of a toric IOL can be an effective and safe choice for patients with cataract and keratoconus. However, predicting the refractive outcome in cataract surgery is difficult in patients with keratoconus, and the surgeon should be aware of different sources of biometric errors and the possible consequences.

Keywords: keratoconus, cataract, astigmatism, phacoemulsification, toric intraocular lens

\section{Introduction}

Keratoconus is a common corneal ectatic disorder characterized by corneal thinning and protrusion of the cornea, resulting in irregular astigmatism and decreased vision. ${ }^{1}$ The disease usually begins at puberty, progresses, and stabilizes in the late $30 \mathrm{~s} .{ }^{1}$ Patients with keratoconus develop cataract at a younger age than patients without the disease. ${ }^{2}$ Cataract surgery in patients with keratoconus can be demanding due to difficulties in selecting the intraocular lens (IOL) and predicting the refractive outcome. The surgery can also be technically challenging due to scarring and thinning of the cornea. When the patient has both corneal astigmatism, because of keratoconus, and cataract, a few studies have reported phacoemulsification with implantation of a toric IOL as a feasible treatment alternative. ${ }^{3-5}$ With a single procedure, both defects are
Correspondence: Madeleine Zetterberg Department of Clinical Neuroscience/ Ophthalmology, Institute of Neuroscience and Physiology, The Sahlgrenska Academy, University of Gothenburg, SE-43I 80 Mölndal, Sweden Tel +46313433255

Fax +4631 4I 2904

Email madeleine.zetterberg@gu.se 
corrected simultaneously. Of these studies, Hashemi et $\mathrm{al}^{3}$ has contributed with the largest study, to our knowledge, with 23 eyes. The purpose of our study was to prospectively evaluate the visual and astigmatic outcomes of cataract surgery with implantation of a toric IOL in patients with keratoconus.

\section{Materials and methods}

This was a prospective study carried out between January 2016 and February 2018. Patients with keratoconus and cataract who were designated a toric IOL were included (4 eyes in total). Preoperatively, the patients were extensively examined, including autorefractor measurements with Auto Kerato-Refractometer (Topcon Medical Systems, Oakland, NJ, USA), best-corrected visual acuity (BCVA), Goldman applanation tonometry, slit-lamp examination, funduscopy, corneal tomography performed with Scheimpflug imaging, and biometry performed with IOLMaster (Carl Zeiss Meditec, Jena, Germany) or immersion ultrasound with OcuScan RxP (Alcon, Fort Worth, TX, USA). Keratoconus was diagnosed based on abnormal posterior elevation and corneal thickness distribution on tomography with Scheimpflug imaging (Pentacam, Oculus, Wetzlar, Germany). ${ }^{6}$ Keratoconus was also diagnosed using the Belin/Ambrosio Enhanced Ectasia Display on Pentacam. ${ }^{7}$ For all patients, the "final D value" was $\geq 2.61$ (Table 1), which has been suggested by Belin et $\mathrm{al}^{7}$ as a cut-off for the disease. Staging of the keratoconus was based on the steepest $K$-value. Mild keratoconus was defined as $K_{\max } \leq 48 \mathrm{D}, 48 \mathrm{D} \geq K_{\max }<52 \mathrm{D}$ was considered moderate, and $K_{\max } \geq 52 \mathrm{D}$ severe keratoconus, as suggested by Thebpatiphat et al. ${ }^{2}$ Inclusion criteria were visually significant cataract, keratoconus, and age $\geq 45$ years. The age limit was set to ensure that the keratoconus was stable. Exclusion criteria were weak zonula fibers, corneal scarring that would compromise the vision for the surgeon during surgery, small pupil, pronounced irregularity of the astigmatism $\left(>15^{\circ}\right)$, and severe keratoconus $\left(K_{\max } \geq 52 \mathrm{D}\right)$.

The selection of the toric IOL was based on $K$-readings from Scheimpflug imaging or IOLMaster readings. The axial length was measured by the IOLMaster for 3 of the patients and with immersion ultrasound biometry, because of very dense cataract, for 1 patient. Haigis formula was used as standard formula for myopic eyes and Hoffer $Q$ formula for eyes with short axial length $(<22 \mathrm{~mm})$. For patient 1 , the simulated $K$-values from Scheimpflug imaging was used in the Hoffer Q formula and the AcrySof IQ toric IOL SN6AT9 (Alcon) with 23.5 D power and target refraction $+0.3 \mathrm{D}$ was chosen. For patient 2, $K$-values from the IOLMaster was used in the Haigis formula and the AcrySof IQ toric IOL SN6AT9 with 15.5 D power and target refraction $-2.67 \mathrm{D}$ was chosen. For patient 3, simulated K-values from Scheimpflug imaging was used in the Haigis formula, the lens chosen was AT Torbi 709M(P) (Carl Zeiss Meditec) with the power +4 D sphere and $+12 \mathrm{D}$ cylinder and target refraction -0.11 . For patient $4, K$-values from Scheimpflug imaging was used in the Haigis formula and AT Torbi $709 \mathrm{M}(\mathrm{P})$ with the power

Table I Demographics and clinical characteristics at baseline

\begin{tabular}{|c|c|c|c|c|}
\hline & Patient I & Patient 2 & Patient 3 & Patient 4 \\
\hline Sex & Female & Male & Male & Male \\
\hline Eye & Right & Left & Left & Right \\
\hline Age (years) & 90 & 67 & 56 & 66 \\
\hline BCVA & $20 / 50$ & $20 / 63$ & $20 / 40$ & Hand motion \\
\hline Axial length (mm) & 21.58 & 25.14 & 26.84 & 24.25 \\
\hline Autorefractor sphere (D) & +4.37 & +1.87 & $\begin{array}{l}\text { No target } \\
-I .5 \text { (subjective refraction) }\end{array}$ & $\begin{array}{l}\text { No target } \\
\pm 0.0 \text { (subjective refraction) }\end{array}$ \\
\hline Autorefractor cylinder (D) & -6.12 & -4.62 & $\begin{array}{l}\text { No target } \\
-9.0 \text { (subjective refraction) }\end{array}$ & $\begin{array}{l}\text { No target } \\
-8.0 \text { (subjective refraction) }\end{array}$ \\
\hline Autorefractor SE (D) & +1.31 & -0.44 & $\begin{array}{l}\text { No target } \\
-6.0 \text { (subjective refraction) }\end{array}$ & $\begin{array}{l}\text { No target } \\
-4.0 \text { (subjective refraction) }\end{array}$ \\
\hline$K_{\max }^{\mathrm{a}}(\mathrm{D})$ & +51.4 & +47.9 & +49.3 & +55.8 \\
\hline Final D value ${ }^{\mathrm{b}}$ & 5.98 & 3.81 & 12.35 & 16.55 \\
\hline $\begin{array}{l}\text { Steepest } K \text {-value from } \\
\text { IOLMaster (D) }\end{array}$ & +50.9 & +49.13 & c & c \\
\hline IOL & AcrySof IQ toric SN6AT9 & AcrySof IQ toric SN6AT9 & AT Torbi 709 M(P) & AT Torbi 709 M(P) \\
\hline IOL power (D) & +23.5 & +15.5 & +4 sphere, + 12 cylinder & +I sphere, +7.5 cylinder \\
\hline Target refraction (D) & +0.3 & -2.67 & -0.11 & +1.5 \\
\hline
\end{tabular}

Notes: ${ }^{2}$ Steepest K-value from Pentacam. 'Belin/Ambrosio Enhanced Ectasia Display from Pentacam. 'No data recorded.

Abbreviations: BCVA, best-corrected visual acuity; SE, spherical equivalent; IOL, intraocular lens. 
$-1.0 \mathrm{D}$ sphere and +7.5 D cylinder and target refraction +1.5 $\mathrm{D}$ was chosen. For all patients, the software provided by the IOL manufacturers was used to calculate the power and the axis orientation of the IOL.

Preoperative marking of the toric IOL axis was performed with the patient in upright position to avoid misalignment due to cyclotorsion, using the RoboMarker (Surgilum, Wilmington, NC, USA). All surgeries were performed by the same experienced surgeon (MZ) at the Sahlgrenska University Hospital, Sweden. Surgery was performed with standard phacoemulsification technique with a main incision of $2.2 \mathrm{~mm}$ under topical and intracameral anesthesia. Postoperatively, a standard regimen of topical steroid antiinflammatory drop dexamethasone 3 times daily for 3 weeks (Novartis Pharma AG, Basel, Switzerland) was employed. Follow-up was performed during the first week (day 1-7), after 4 weeks, and for 2 of the patients after 5 or 7 months.

\section{Ethics approval and informed consent}

Ethics approval and consent was granted by the Regional Ethical Review Board in Gothenburg, reference number Dnr 561-15. Written informed consent for publication including accompanying data and images were obtained from the patients for this study.

\section{Results}

The study population in this prospective study consisted of 1 female and 3 males (4 eyes). Table 1 shows baseline parameters of the 4 patients. In all patients, BCVA increased and astigmatism decreased after the cataract surgery and implantation of a toric IOL. Table 2 shows outcome with regard to BCVA and astigmatism. Regarding complications, no misalignment of the axis for the IOL was observed, and no complications other than those described below were noted in any patient.

\section{Patient I}

A 90-year-old woman was diagnosed with bilateral cataract and keratoconus that was previously unknown. The astigmatism was regular (Figure 1) and the patient used to wearing progressive eye glasses. Nine months before surgery, the patient had a retinal arterial occlusion in the right eye. Preoperatively, pseudoexfoliations were noticed in the right eye. Both eyes were planned for cataract surgery with toric IOLs, but after surgery was performed in the right eye the patient declined further surgery of the left eye. The BCVA increased from 20/50 to 20/40 and the astigmatism (cylinder measure from autorefractor) decreased from -6.12 to $-3.75 \mathrm{D}$. The patient developed posterior capsular opacification after 2 months and was treated with Nd:YAG laser capsulotomy.

Table 2 Visual and astigmatism (cylinder according to autorefractor) outcomes

\begin{tabular}{|c|c|c|c|c|}
\hline & Patient I & Patient 2 & Patient 3 & Patient 4 \\
\hline \multicolumn{5}{|l|}{ BCVA } \\
\hline Preoperative & $20 / 50$ & $20 / 63$ & $20 / 40$ & Hand motion \\
\hline Day I-7 & $20 / 50$ & $20 / 25$ & $20 / 63$ & $20 / 200$ \\
\hline Week 4 & $20 / 40$ & $20 / 32$ & $20 / 63$ & $20 / 63$ \\
\hline Month 5-7 & a & $20 / 20$ & $20 / 32$ & a \\
\hline \multicolumn{5}{|c|}{ Autorefractor cylinder (D) } \\
\hline \multirow[t]{2}{*}{ Preoperative } & -6.12 & -4.62 & No target & No target \\
\hline & & & -9.0 (subjective refraction) & -8.0 (subjective refraction) \\
\hline Day I-7 & -3.75 & -1.5 & -2.0 & \pm 0.0 (subjective refraction) \\
\hline Week 4 & $-I .5$ (subjective refraction) & -1.5 & -2.0 & -2.75 \\
\hline Month 5-7 & a & -1.75 & -3.0 & a \\
\hline \multicolumn{5}{|l|}{ Autorefractor SE (D) } \\
\hline \multirow[t]{2}{*}{ Preoperative } & +1.31 & -0.44 & No target & No target \\
\hline & & & -6.0 (subjective refraction) & -4.0 (subjective refraction) \\
\hline Day I-7 & +0.125 & -2.0 & +0.5 & $+\mathrm{I} .5$ (subjective refraction) \\
\hline Week 4 & -0.75 (subjective refraction) & -2.5 & \pm 0.0 & -2.125 \\
\hline Month 5-7 & a & -2.4 & +0.25 & a \\
\hline Target refraction (D) & +0.3 & -2.67 & -0.11 & +1.5 \\
\hline $\mathrm{BPE}^{\mathrm{b}}(\mathrm{D})$ & $-0.18 \mathrm{D}$ (at I week) & +0.30 D (at 7 months) & +0.36 (at 3 months) & $-3.63 \mathrm{D}$ (at 4 weeks) \\
\hline
\end{tabular}

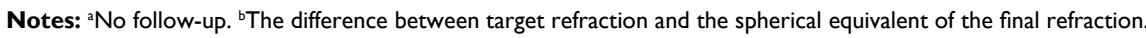

Abbreviations: BCVA, best-corrected visual acuity; SE, spherical equivalent; BPE, biometry prediction error. 


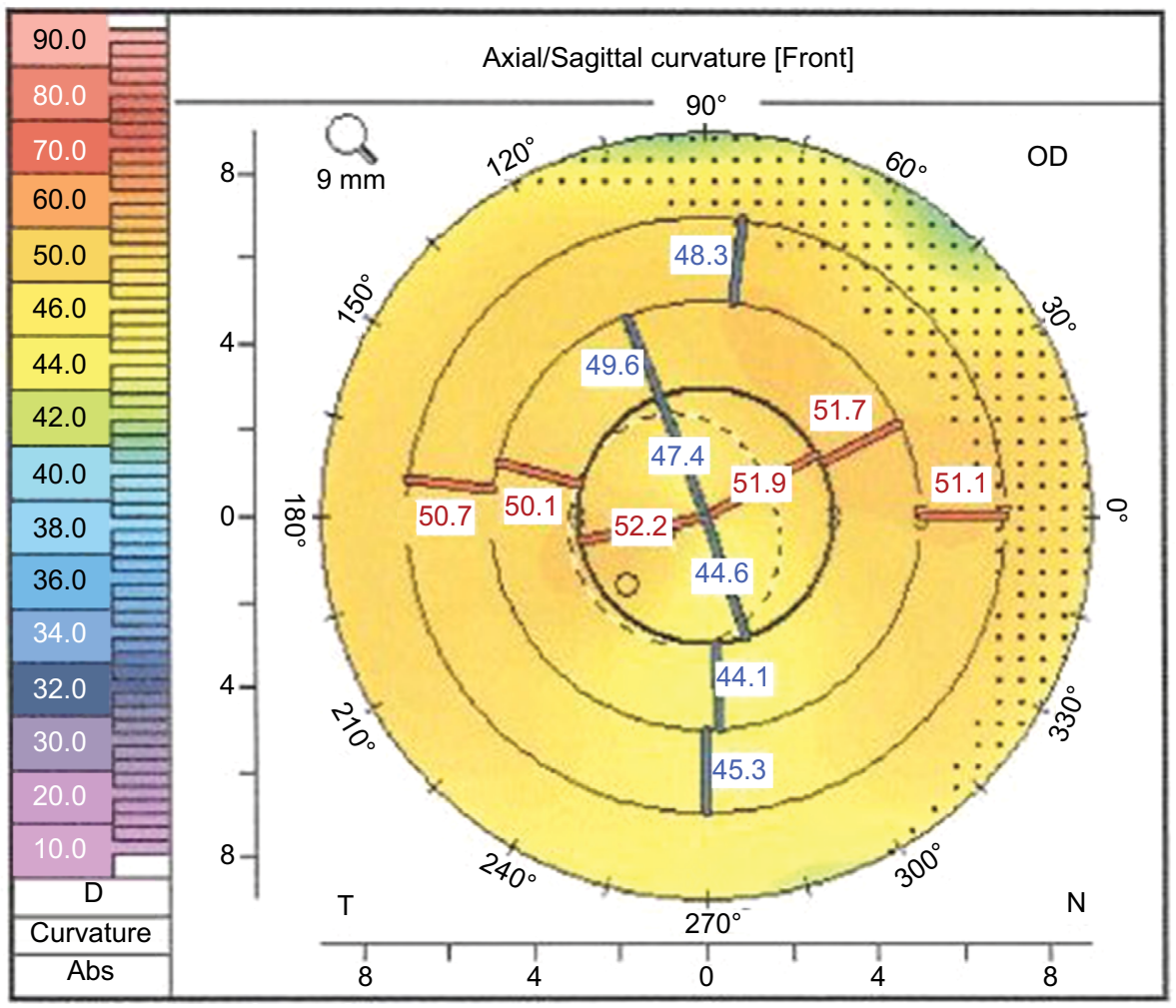

Figure I Scheimpflug imaging (Pentacam, Oculus) of the corneal front surface in patient I.

\section{Patient 2}

This patient was a 67-year-old man with bilateral cataract and previously undiagnosed keratoconus. The astigmatism was slightly irregular (Figure 2). The patient used to wear glasses for long distance but used no correction for near vision. In the right eye, phacoemulsification and implantation of a spherical IOL was performed because the astigmatism was $<-3.0$ D. In the left eye, with higher astigmatism, a toric IOL was implanted. The BCVA, in the left eye, increased from $20 / 63$ to $20 / 20$ and the astigmatism (cylinder measure from autorefractor) decreased from -4.62 to $-1.75 \mathrm{D}$.

\section{Patient 3}

A 56-year-old man with known keratoconus presented with cataract in the left eye. Ten years earlier, Intacs was implanted in the right eye, and 2 years after that cataract extraction and implantation of a spherical IOL was performed. The patient could not tolerate contact lenses and wore eye glasses. In the left eye, which was included in this study, astigmatism was regular (Figure 3). BCVA increased from 20/40 to 20/32 and the astigmatism decreased from $-9.0 \mathrm{D}$ (cylinder measure from subjective refraction) to $-3.0 \mathrm{D}$ (cylinder measure from autorefractor). Autorefractor could not be performed preoperatively because of high astigmatism. Postoperatively, the patient suffered from pseudophakic cystoid macular edema and was treated with topical nonsteroidal drop Nepafenac (Novartis Pharma AG) and steroid anti-inflammatory drop dexamethasone. At 6 months follow-up, the edema had resolved and the BCVA was satisfactory, 20/32 (preoperative BCVA was 20/40).

\section{Patient 4}

A 66-year-old man with known keratoconus had developed dense cataract in the right eye. Cataract extraction and implantation of a spherical IOL had been performed earlier in the left eye. The astigmatism in the right eye was regular (Figure 4). The patient could not tolerate contact lenses and wore eye glasses instead. The right eye was included in this study. The BCVA increased from hand motion to 20/40 and the astigmatism decreased from $-8.0 \mathrm{D}$ (cylinder measure from subjective refraction) to $-2.75 \mathrm{D}$ (cylinder measure from autorefractor). Autorefractor could not be performed preoperatively because of high astigmatism.

\section{Discussion}

Implantation of a toric IOL after phacoemulsification because of cataract in patients with keratoconus has its pitfalls. However, this study and a few earlier reports present promising 


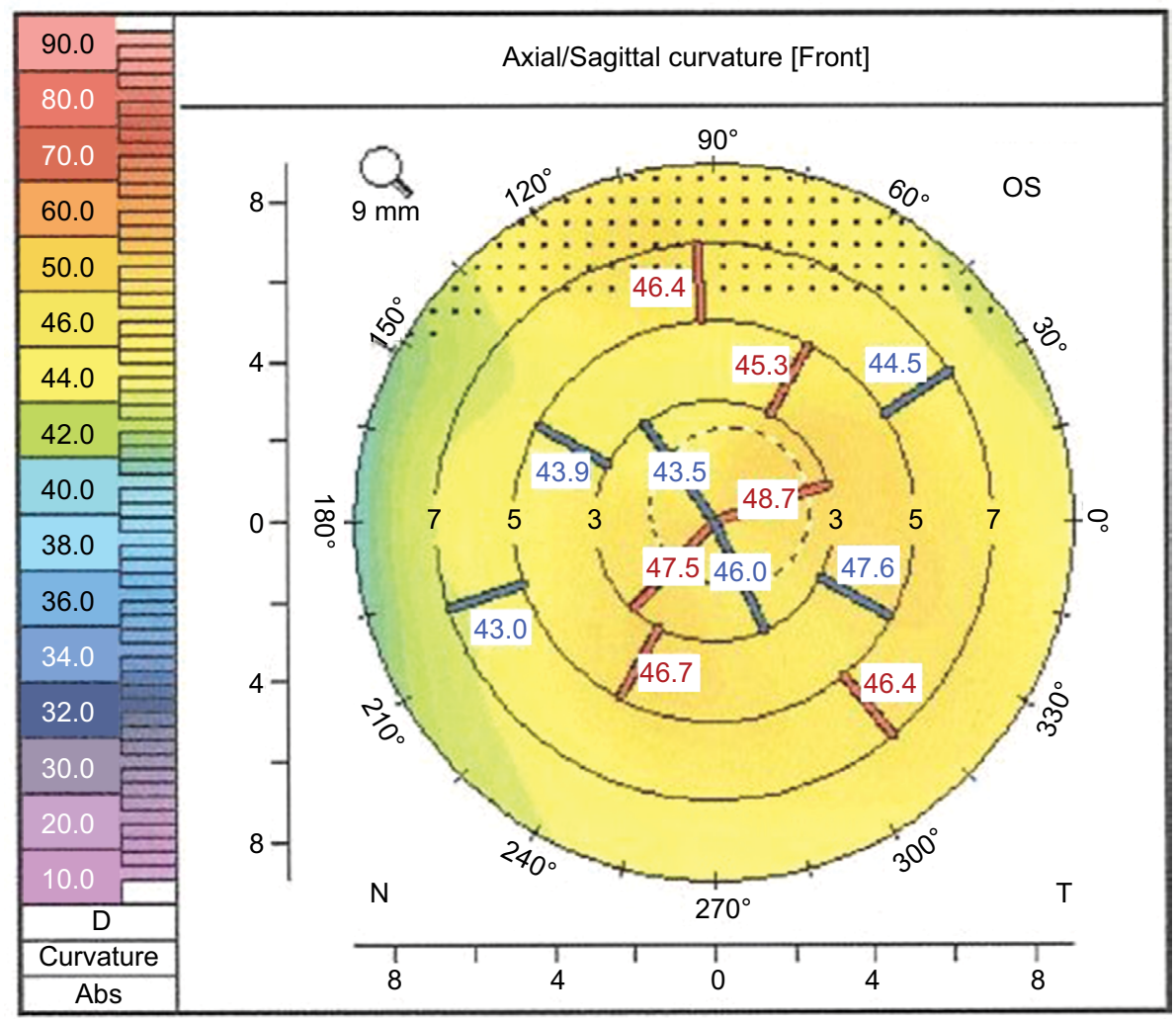

Figure 2 Scheimpflug imaging (Pentacam, Oculus) of the corneal front surface in patient 2.

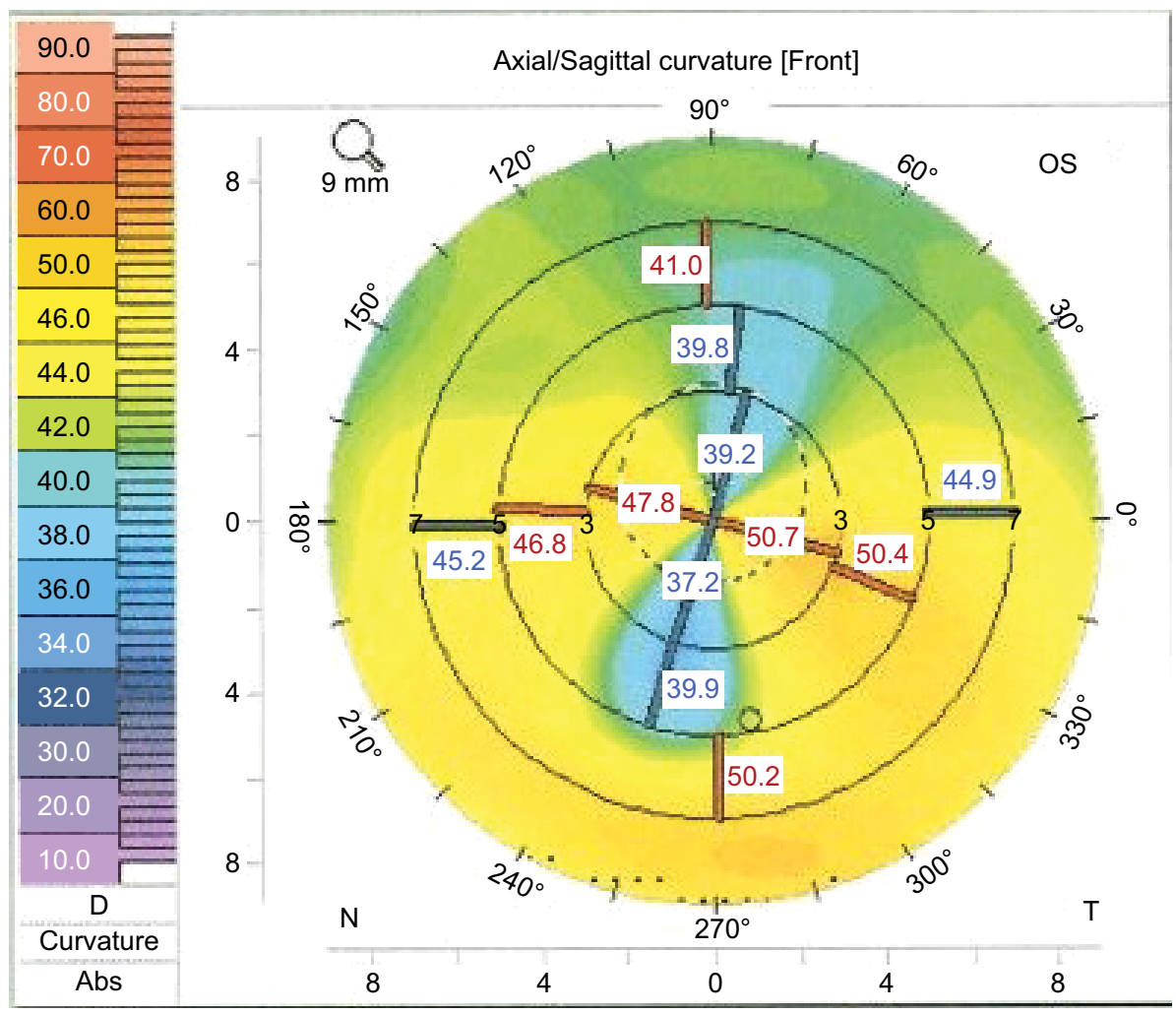

Figure 3 Scheimpflug imaging (Pentacam, Oculus) of the corneal front surface in patient 3. 


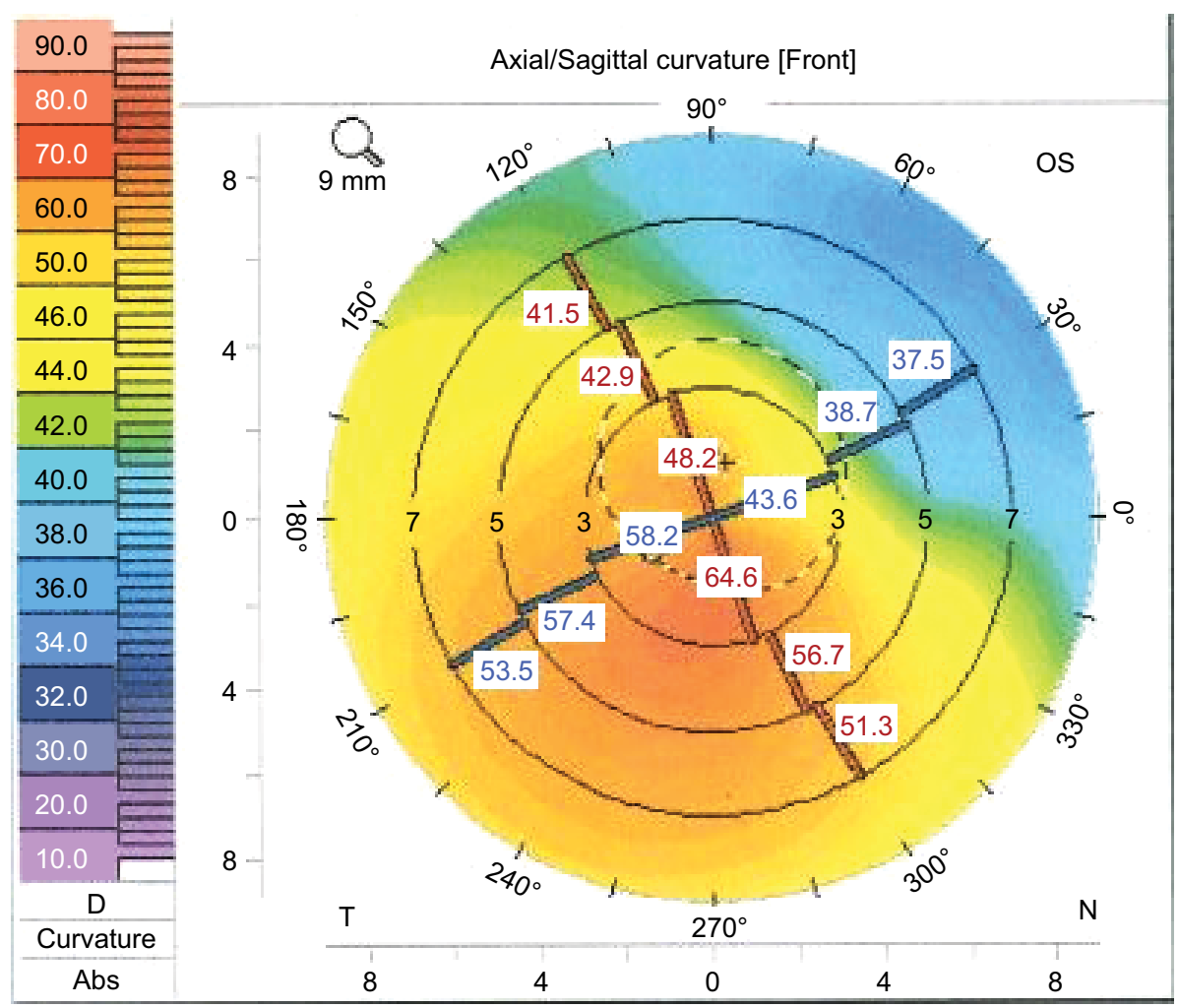

Figure 4 Scheimpflug imaging (Pentacam, Oculus) of the corneal front surface in patient 4.

results with improvements in BCVA and astigmatism and a low frequency of complications. ${ }^{3-5}$ Nonetheless, performing cataract surgery in patients with keratoconus needs planning and careful considerations.

The first consideration with this category of patients is the diagnosis criteria of keratoconus. Keratoconus is problematic to define and diagnose, and other ectatic disorders can resemble keratoconus. We have used the appearance of the corneal posterior elevation, corneal thickness distribution, and Belin/Ambrosio index on Scheimpflug imaging to diagnose keratoconus, but the difficulties in diagnosing keratoconus is a limitation of this study.

Accurate keratometry measurements are difficult, which results in inaccurate corneal power estimates and difficulties in selecting the power of the IOL. ${ }^{8,9}$ In eyes with keratoconus, it cannot be assumed that the measured $K$ is equal to the $K$ at visual axis nor that the effect of the measurement error is uniform for all keratometric values. ${ }^{9}$ Watson et $\mathrm{al}^{9}$ found that conventional biometry (IOLMaster) will overestimate the corneal power and underestimate the IOL power in eyes with keratoconus, resulting in postoperative hyperopia. In eyes with $K_{\max } \leq 55 \mathrm{D}$, these effects are usually small, and using $K$-values from the IOLMaster results in acceptable refractive outcomes. ${ }^{9}$ Hashemi et al ${ }^{10}$ compared 5 different keratometry measurements (from Pentacam, Orbscan, IOLMaster, Eyesys, and manual Javal) and also found good repeatability of $K$-values up to $55 \mathrm{D}$ with all devices. In $K_{\max }$ $\geq 55 \mathrm{D}$, all devices had low repeatability. ${ }^{10}$

The difference between the planned refraction and the spherical equivalent of the final refraction is defined as the biometry prediction error (BPE). ${ }^{9}$ Watson et $\mathrm{al}^{9}$ found that in mild keratoconus (defined as $K_{\max } \leq 48 \mathrm{D}$ ) BPE was $\pm 0 \mathrm{D}$ and in moderate keratoconus $\left(K_{\max } 48-55 \mathrm{D}\right) \mathrm{BPE}$ was $-0.3 \mathrm{D}{ }^{9}$ In severe keratoconus $\left(K_{\max } \geq 55 \mathrm{D}\right)$, BPE was $+6.8 \mathrm{D}$ when using actual measured $K$-values but only $+0.6 \mathrm{D}$ when using standard $K$-values (43.25 D). ${ }^{9}$ In our study (all patients had $K_{\max }<55 \mathrm{D}$ and actual $K$-values were used), the BPE varied from $+0.36 \mathrm{D}$ (patient 3 at 5 months postoperatively) to -3.63 $\mathrm{D}$ (patient 4 at 4 weeks postoperatively). Patient 1 had a BPE of $-0.18 \mathrm{D}$ at 1 week postoperatively, and patient 2 had a BPE of $+0.30 \mathrm{D}$ at 7 months postoperatively.

A concern with toric IOLs is rotational stability. Postoperative rotation of $1^{\circ}$ results in $3 \%$ loss of the cylinder power, and with a rotation of $30^{\circ}$ the cylinder power of the toric IOL is completely abolished. ${ }^{11}$ According to Tognetto et al, ${ }^{12}$ who not only analyzed the loss of cylinder power but also the image quality, IOL rotation within $10^{\circ}$ did not affect the image quality. With a rotation of $45^{\circ}$, however, $100 \%$ of 
the toric correction is lost. ${ }^{12}$ We did not see any significant lens rotation on examination in the biomicroscope. The largest lens rotation was in patient 1 where the lens, 1 week postoperatively, had rotated $8^{\circ}$ (from $19^{\circ}$ to $27^{\circ}$ ). However, BCVA had increased and the astigmatism had decreased.

\section{Conclusion}

A limitation of this study is the small number of patients (only 4 eyes), but nevertheless results are well in line with the few previously published reports, demonstrating that cataract surgery with implantation of a toric IOL can be a good and safe option for patients with keratoconus. However, predicting the refractive outcome in cataract surgery is difficult in patients with keratoconus and the surgeon should be aware of different sources of biometric errors and the possible consequences.

\section{Acknowledgment}

The research was funded by the Swedish government ("Agreement concerning research and education of doctors"; ALF-GBG-145921) and Göteborg Medical Society.

\section{Author contributions}

$\mathrm{MZ}$ performed the cataract surgeries. KA was a major contributor in the pre- and postoperative examinations. Both authors contributed toward data analysis, drafting and critically revising the paper and agree to be accountable for all aspects of the work.

\section{Disclosure}

The authors report no conflicts of interest in this work.

\section{References}

1. Rabinowitz YS. Keratoconus. Surv Ophthalmol. 1998;42(4):297-319.

2. Thebpatiphat N, Hammersmith KM, Rapuano CJ, Ayres BD, Cohen EJ. Cataract surgery in keratoconus. Eye Contact Lens. 2007;33(5): 244-246.

3. Hashemi H, Heidarian S, Seyedian MA, Yekta A, Khabazkhoob M. Evaluation of the results of using toric IOL in the cataract surgery of keratoconus patients. Eye Contact Lens. 2015;41(6):354-358.

4. Kamiya K, Shimizu K, Miyake T. Changes in astigmatism and corneal higher-order aberrations after phacoemulsification with toric intraocular lens implantation for mild keratoconus with cataract. Jpn J Ophthalmol. 2016;60(4):302-308.

5. Nanavaty MA, Lake DB, Daya SM. Outcomes of pseudophakic toric intraocular lens implantation in keratoconic eyes with cataract. $J$ Refract Surg. 2012;28(12):884-890.

6. Gomes JA, Tan D, Rapuano CJ, et al. Global consensus on keratoconus and ectatic diseases. Cornea. 2015;34(4):359-369.

7. Belin MW, Villavicencio OF, Ambrósio RR Jr. Tomographic parameters for the detection of keratoconus: suggestions for screening and treatment parameters. Eye Contact Lens. 2014;40(6):326-330.

8. Leccisotti A. Refractive lens exchange in keratoconus. $J$ Cataract Refract Surg. 2006;32(5):742-746.

9. Watson MP, Anand S, Bhogal M, et al. Cataract surgery outcome in eyes with keratoconus. Br J Ophthalmol. 2014;98(3):361-364.

10. Hashemi H, Yekta A, Khabazkhoob M. Effect of keratoconus grades on repeatability of keratometry readings: comparison of 5 devices. $J$ Cataract Refract Surg. 2015;41(5):1065-1072.

11. Horn JD. Status of toric intraocular lenses. Curr Opin Ophthalmol. 2007;18(1):58-61.

12. Tognetto D, Perrotta AA, Bauci F, et al. Quality of images with toric intraocular lenses. J Cataract Refract Surg. 2018;44(3):376-381.
International Medical Case Reports Journal

\section{Publish your work in this journal}

The International Medical Case Reports Journal is an international, peer-reviewed open-access journal publishing original case reports from all medical specialties. Previously unpublished medical posters are also accepted relating to any area of clinical or preclinical science. Submissions should not normally exceed 2,000 words or

\section{Dovepress}

4 published pages including figures, diagrams and references. The manuscript management system is completely online and includes a very quick and fair peer-review system, which is all easy to use. Visit http://www.dovepress.com/testimonials.php to read real quotes from published authors. 